\title{
Espaçamento entre linhas e densidade de semeadura em revegetação com espécie de tremoço visando à recuperação de solo degradado
}

\author{
Row space and sowing density in revegetation with lupin species in degraded soil restoration
}

\author{
Ana Paula Moreira Rovedder ${ }^{*}$ Flávio Luiz Foletto Eltz ${ }^{\mathrm{II}}$ Marta Sandra Drescher ${ }^{\mathrm{II}}$ \\ Fabiana de Oliveira Dorneles ${ }^{\mathrm{II}}$ Ricardo Bergamo Schenato ${ }^{\mathrm{III}}$
}

\section{RESUMO}

A degradação do solo pela arenização no sudoeste do Rio Grande do Sul precisa ser controlada e, para isso, a revegetação é uma técnica eficiente e de baixo custo. A possibilidade de se utilizar uma espécie nativa da região para tais medidas de controle surge como uma alternativa viável do ponto de vista econômico e ecológico. O objetivo deste estudo foi testar a melhor maneira de cultivar Lupinus albescens Hook. \& Arn., um tremoço nativo da região, visando à contenção da arenização. $O$ experimento foi conduzido em uma área degradada em Alegrete, Rio Grande do Sul (RS), sul do Brasil. Os tratamentos foram espaçamentos com distância de 17, 34 e $51 \mathrm{~cm}$ entre as linhas de plantio e número de plantas por metro linear $(4,8,12,16$ e 20 plantas por metro linear). Os parâmetros analisados foram produção de biomassa na parte aérea, acúmulo de macronutrientes na biomassa da parte aérea, produção de sementes, peso e número de nódulos de fixação biológica de nitrogênio $(F B N)$. Foi realizada análise da variância. Não houve interação significativa entre os dois fatores estudados. O fator espaçamento entre linhas (EL) produziu variação significativa para as diversas variáveis estudadas, com exceção do P acumulado na parte aérea. No caso do espaçamento entre linha, a análise da variância foi complementada por análise de regressão, e o valor para cada característica analisada foi estimado a partir dos modelos matemáticos gerados. O espaçamento entre linhas de $17 \mathrm{~cm}$ favoreceu a produção de biomassa e o acúmulo de macronutrientes na biomassa da parte aérea, além do peso de nódulos de $F B N$. O espaçamento de $51 \mathrm{~cm}$ foi mais eficiente para produção de sementes por planta. Conclui-se que, para plantios de contenção da arenização, o espaçamento de $17 \mathrm{~cm}$ é mais eficiente, enquanto que, para plantios que objetivam produzir sementes, o espaçamento de $51 \mathrm{~cm}$ é melhor.
Palavras-chave: Lupinus albescens Hook. \& Arn, Bioma Pampa, biomassa vegetal, fixação biológica de nitrogênio.

\begin{abstract}
The soil degradation by sandization in the Southwest of Rio Grande do Sul needs to be controlled and, therefore, revegetation is an efficient and low cost technique. The possibility to use a native species from this region for such control measures appears as a viable alternative in economical and ecological terms. The objective of this study was to test the more efficient way to crop Lupinus albescens Hook. \& Arn., a native local plant, aiming sandization contention. The experiment was carried out in a degraded area located in Alegrete, RS, Southern Brazil. The treatments were spaced at a distance of 17,34 and $51 \mathrm{~cm}$ between rows plantation and number of plants by linear meter $(4,8,12,16$ and 20 plants in each linear meter). The analyzed parameters were canopy biomass production, macronutrients in canopy biomass, seed production, weight and number of root nodules responsible by biological nitrogen fixation. The analysis of variance analysis was performed and there was no interaction between the factors. The row space produced significant variation for several variables, except for accumulated $P$ in the canopy biomass. The number of plants by linear meter did not interfere on the characteristics analyzed. For the row space, the analysis of variance was complemented by regression analysis and the value for each analyzed characteristic, estimated by mathematical models. The row space of $17 \mathrm{~cm}$ favored the production and macronutrients accumulation in canopy biomass, besides the weight of FBN nodules. Row space of $51 \mathrm{~cm}$ was most efficient for seeds production. It was concluded that for crops that aims contention of sandization, row space of $17 \mathrm{~cm}$ is more efficient, while for crops that aims to produce seeds, row space of $51 \mathrm{~cm}$ is better.
\end{abstract}

Key words: Lupinus albescens Hook. \& Arn, Pampa Bioma, vegetal biomass, biological nitrogen fixation.

'Universidade Federal de Santa Maria (UFSM), Campus Silveira Martins, Rua Francisco Guerino, 707, 97195-000, Silveira Martins, -RS, Brasil. E-mail: anarovedder@ smail.ufsm.br. *Autor para correspondência.

IIPrograma de Pós-graduação em Ciência do Solo, UFSM, Santa Maria, RS, Brasil.

II'Universidade Federal do Pampa (UNIPAMPA), Campus Alegrete, Alegrete, RS, Brasil. 


\section{INTRODUÇÃO}

Os processos de degradação do solo podem ser entendidos como perturbações nos fluxos de troca, as quais se ampliam por todo o sistema, alterando seu funcionamento e produzindo uma nova realidade, ou seja, o solo degradado (AZEVEDO \& KAMINSKI, 1995). O principal objetivo das práticas de recuperação de solos e ecossistemas degradados é o retorno a condições mais desejáveis possíveis, envolvendo a composição original de espécies e a estrutura da comunidade (D'ANTONIO \& MEYERSON, 2002). Para tanto, KAGEYAMA et al. (1989) recomendam utilizar espécies nativas dos locais a serem recuperados como tentativa de manter-se a estrutura ecossistêmica original.

O Bioma Pampa, no Rio Grande do Sul, tem sido ameaçado por processos de degradação da qualidade do solo, de suas funções ecossistêmicas e da composição fitossociológica. Uma das expressões dessa degradação é o fenômeno da arenização que ocorre no sudoeste gaúcho, entendido como o retrabalhamento dos solos arenosos pela ação dos agentes erosivos (SUERTEGARAY, 1998). Nas áreas afetadas, surgem focos de arenização, conhecidos regionalmente como areais, com perda da cobertura vegetal por efeito abrasivo e soterramento e, consequentemente, exposição do solo. Devido ao baixo grau de resiliência do ecossistema, uma vez estabelecido o areal, este tende a expandir-se indefinidamente sobre a área de campo ao redor.

No âmbito das atividades multidisciplinares de recuperação de áreas degradadas, o método de revegetação do solo tem adquirido importância por tratar-se de uma técnica que promove o retorno a condições desejáveis do ambiente edáfico por meio do uso de espécies vegetais eficientes em adaptar-se a solos degradados. O uso de plantas para cobertura e proteção do solo, bem como para a ciclagem de nutrientes, vêm sendo relatado desde a Idade Antiga (CALEGARI et al., 1993), passando pela Idade Média (COSGROVE, 1991), até os dias atuais (BOLDES et al., 2002). Esses princípios também vêm sendo utilizados na recuperação de solos degradados por meio de estratégias de revegetação (KERSTIN \& LUNDMARK, 1988; SANTOS et al., 2001).

A revegetação seria uma alternativa viável para a recuperação de solos arenizados, contudo a tarefa de apontar quais as estratégias mais adequadas para a solução ou amenização do problema é complexa, embora a experiência demonstre que as alternativas podem ser simples e acessíveis ao produtor rural. Uma das dificuldades está na seleção de qual ou quais espécies vegetais poderiam fazer parte de projetos de revegetação dos areais de forma satisfatória. Mais recentemente, tem sido discutido e frequentemente criticado o uso de espécies exóticas para a recuperação de áreas degradadas (SUERTEGARAY, 1995; D'ANTONIO \& MEYERSON, 2002). No âmbito do Bioma Pampa, o uso de espécies exóticas, principalmente o pinus (Pinus sp.) e o eucalipto (Eucalyptus sp.), tanto para recuperação, quanto para sistemas de produção, tem sido duramente contestado, sendo alegadas duas questões: a fragilidade do solo e a necessidade de conservação da florística campestre (SUERTEGARAY, 1998; PILLAR et al.; 2006).

Uma alternativa mais complexa consiste na recomposição da estrutura ecossistêmica atingida pela arenização. Uma das principais vantagens desse método seria a possibilidade de reincorporar tais áreas ao uso pecuário, principal atividade econômica da região. Contudo, essa possibilidade é dificultada pela baixa resiliência do sistema, o que pode tornar necessário um longo tempo para ser alcançada. Salientase que ainda não há dados científicos que permitam propor um período de tempo necessário para o retorno do local afetado aos processos produtivos. Muito provavelmente, se esse objetivo se concretizasse, deveria ser dada preferência à utilização com pecuária com baixa lotação de campo, mantendo-se a cobertura nativa. Para se alcançar pelo menos a contenção da arenização e, em um segundo momento, a recomposição da estrutura vegetal, devem ser utilizadas espécies que permitam o retorno da composição florística original, incentivando a atuação dos mecanismos e processos de colonização e regeneração natural do ecossistema (RESENDE \& KONDO, 2001), e evitadas aquelas que possam resultar em efeitos alelopáticos sobre a vegetação natural. Além disso, o aumento de informações quanto ao uso, à estrutura e à formação de ecossistemas nativos possibilita o desenvolvimento de estratégias de manejo sustentável destes, bem como a formação de alternativas em atividades econômicas e de caráter ambiental.

A partir desses pressupostos, testou-se como estratégia de recuperação de solos arenizados a revegetação com Lupinus albescens, fabácea nativa do Bioma Pampa conhecida como tremoço, com o objetivo de conter os mecanismos da arenização, estabilizando-se o substrato arenoso. A partir da colonização da área pelo $\boldsymbol{L}$. albescens, obtém-se a redução dos processos erosivos, típicos da arenização, ocorrendo a estabilização do local afetado e permitindo a posterior recolonização da área pelas demais espécies nativas (ROVEDDER \& ELTZ, 2008). Com o objetivo de se definir uma forma de cultivo do L. albescens que 
seja mais eficiente para a contenção da arenização, foram testados densidade de semeadura e espaçamento entre linhas diferentes. Este trabalho se justifica pela necessidade de serem encontradas alternativas locais para conter o processo de degradação dos solos arenosos do sudoeste rio-grandense, o qual vem ocasionando a perda da capacidade produtiva e da biodiversidade do Bioma Pampa, intensificando-se com o aumento da ocupação populacional. Além disso, torna-se cada vez mais importante a ampliação de conhecimentos sobre o germoplasma nativo, frente à ocupação antrópica dos ecossistemas naturais.

\section{MATERIAL E MÉTODOS}

O sudoeste do Rio Grande do Sul está localizado entre as latitudes de $29^{\circ} 00^{\prime} \mathrm{S}$ e $31^{\circ} 00^{\prime} \mathrm{S}$ e entre as longitudes de $54^{\circ} 30^{\prime} \mathrm{W}$ e $58^{\circ} 45^{\prime} \mathrm{W}$, fazendo parte da região fisiográfica denominada de Campanha Gaúcha. Predomina na região o Bioma Pampa, o qual abrange os campos da região das Missões, do Planalto Médio e de toda a Metade Sul do Estado. Nesta última, se inserem os campos da Campanha Gaúcha, da Serra do Sudeste e do Litoral (IBGE, 2004). De acordo com Koeppen, o clima da região está classificado como Cfa, subtropical úmido, sem estação seca e com temperaturas médias variando de $14,3^{\circ} \mathrm{C}$ no inverno a $26,3^{\circ} \mathrm{C}$ no verão, com uma média de precipitações anuais de $1.400 \mathrm{~mm}$ (MORENO, 1961). A vegetação regional apresenta aspectos de xeromorfia, sendo por isso considerada uma vegetação testemunha de um período semiárido ou semiúmido estepário, o qual sofreu uma umidificação a partir do Holoceno (SUERTEGARAY, 1995).

Para o desenvolvimento da pesquisa, foi escolhido um núcleo de arenização localizado nas coordenadas $29^{\circ} 40^{\prime} 05^{\prime \prime}$ de latitude sul e $55^{\circ} 19^{\prime} 40^{\prime \prime}$ de longitude oeste. A área do núcleo pertence à Fazenda Santo Antão, localizada no município de Alegrete, localidade de Cerro do Tigre. De acordo com o histórico levantado junto aos proprietários, a área é utilizada com pecuária, e a arenização iniciou-se há 20 anos, a partir das estrias de caminhamento do gado. Em recobrimento realizado com aparelho de GPS (Global Positioning System), em novembro de 2005, constatouse que o núcleo de arenização apresentava cerca de 10 ha de extensão. O solo é classificado como Neossolo Quartzarênico distrófico (EMBRAPA, 2006), com saturação por bases de $10 \%$, saturação por alumínio de $63 \%$ e percentual de matéria orgânica de $0,4 \%$, conforme análise química realizada por métodos descritos em TEDESCO et al., (1995). A análise granulométrica, realizada pelo método da pipeta, apresentou resultado de $92,90 \%$ de areia, $0,80 \%$ de silte e 6,30\% de argila.
O experimento foi instalado em delineamento de blocos ao acaso, em esquema bifatorial $4 \times 5$, com parcelas subdivididas e quatro repetições. $\mathrm{O}$ fator espaçamento entre linhas de semeadura foi estabelecido sobre parcelas de 5x6m, enquanto o fator densidade de semeadura por metro linear foi estabelecido em subparcelas de $1 \times 6 \mathrm{~m}$. Os valores de espaçamento entre linhas foram compatíveis com semeadoras utilizadas em sistema plantio direto: 17,34 e $51 \mathrm{~cm}$. Na linha de semeadura, foram comparadas densidades de 4, 8, 12, 16 e 20 plantas por metro linear. Com o objetivo de não inibir a nodulação do tremoço, não foi realizada adubação nitrogenada. As parcelas foram adubadas com $120 \mathrm{~kg} \mathrm{ha}^{-1}$ de $\mathrm{K}_{2} \mathrm{O}$ e $120 \mathrm{~kg} \mathrm{ha}^{-1}$ de $\mathrm{P}_{2} \mathrm{O}_{5}$, distribuídos a lanço, de acordo com recomendação para o gênero Lupinus sp. (CQFS-RS/SC, 2004). As sementes de $\boldsymbol{L}$. albescens foram coletadas em área de ocorrência natural da espécie. Como forma de inoculação das parcelas com a estirpe bacteriana simbiótica ao $\boldsymbol{L}$. albescens, as sementes foram misturadas com solo oriundo de maciço natural da espécie, uma vez que, sendo uma espécie nativa e não utilizada comercialmente, não há produção comercial do inóculo específico. Essa metodologia de inoculação tem sido adotada em experimentos para cobertura e recuperação do solo com outras espécies do gênero Lupinus (KERSTIN \& LUNDMARK, 1988).

As variáveis avaliadas foram a biomassa produzida na parte aérea até o florescimento, o conteúdo de macronutrientes acumulados (nitrogênio, fósforo, potássio, cálcio e magnésio) na parte aérea até o florescimento, a produção de sementes e o número e peso de nódulos nas raízes. Para tanto, foi coletado o número de plantas equivalente às encontradas em um metro linear por subparcela. O material coletado foi seco em estufa a $60^{\circ} \mathrm{C}$, até peso constante. Para o conteúdo de macronutrientes, foi realizada análise de tecido vegetal, de acordo com TEDESCO et al. (1995). Foi realizada a análise de variância dos dados obtidos e, quando significativa $(\mathrm{P}<0,05)$, complementada pela análise de regressão.

\section{RESULTADOS E DISCUSSÃO}

Não houve interação significativa entre os dois fatores estudados. Na avaliação da densidade de semeadura por metro linear, não houve diferenças entre os tratamentos $(\mathrm{P}<0,05)$ para todos os parâmetros analisados. $\mathrm{O}$ fator espaçamento entre linhas (EL) produziu variação significativa para as diversas variáveis estudadas, com exceção do $\mathrm{P}$ acumulado na biomassa da parte aérea. A inexistência de interação significativa entre os fatores estudados e a ausência 
de variação significativa para densidade de semeadura (DS), provavelmente, estão relacionadas à plasticidade fenotípica da espécie, a qual se encontra em estado selvagem, sem nenhum tipo de melhoramento genético, uma vez que é uma espécie nativa do Bioma Pampa e não cultivada comercialmente. Embora ocorram espécies cultivadas, principalmente as europeias, o gênero Lupinus é reconhecido por sua ampla distribuição geográfica e adaptação a diferentes condições climáticas, apresentando ampla gama de espécies selvagens, principalmente no continente americano (NAGANOWSKA et al., 2003).

A presença de tegumento duro na semente também pode estar envolvida com a alta variabilidade encontrada. No presente estudo, não foi realizado nenhum tipo de tratamento para quebra de dormência, pois se esperava que a temperatura da época de semeadura e a própria movimentação das partículas de areia poderiam ser suficientes para fazer a escarificação necessária das sementes, uma vez que a quebra de dormência no gênero está relacionada à diminuição da temperatura ambiente e à escarificação mecânica (GISLER, 2004). Na região sudoeste do Rio Grande do Sul, o L. albescens inicia sua germinação em maio e pode continuar até agosto. O contato da semente com as partículas arenosas gera efeito de escarificação mecânica no tegumento duro, o que pode representar um mecanismo da coevolução da espécie com as condições edafoclimáticas da região, gerando características adaptativas altamente eficientes.

A tabela 1 apresenta os modelos matemáticos ajustados pela análise de regressão, que descrevem o comportamento das diversas variáveis estudadas frente à variação do espaçamento entre linhas. A tabela 2 apresenta os valores estimados para a produção de biomassa da parte aérea e o acúmulo de macronutrientes nessa. Nota-se que o menor espaçamento entre linhas $(17 \mathrm{~cm})$ favoreceu essas características. Esse resultado possivelmente está relacionado à maior velocidade de cobertura do solo, à formação de um microclima sob as plantas e, ainda, a uma possível redução do efeito de abrasão das plantas. A maior proximidade entre as linhas diminui a velocidade do vento na superfície do solo, com significativa redução da movimentação de partículas de areia, o que beneficia o desenvolvimento vegetal sobre o solo arenizado.

Esses resultados demonstram que a espécie poderia suportar maiores densidades populacionais sem prejuízo à produção de biomassa, o que seria vantajoso do ponto de vista da proteção e/ou recuperação dos solos arenosos da região, pois a maior proximidade entre plantas no espaçamento de $17 \mathrm{~cm}$ favoreceria a cobertura mais rápida do solo e a contenção da movimentação de partículas, com maior potencial de cobertura do solo e de ciclagem de nutrientes. O espaçamento de $17 \mathrm{~cm}$ também se destacou na característica peso de nódulos de FBN, com maior valor estimado pela análise de regressão, enquanto que, para número de nódulos de FBN, as estimativas geradas para os três espaçamentos foram mais semelhantes entre si. Não foram encontrados outros relatos de estudos com $\boldsymbol{L}$. albescens como planta recuperadora, impedindo que sejam feitas comparações com os resultados aqui apresentados. ZABOT et al. (2004), trabalhando com feijão preto, outra fabácea, encontraram aumento na produção de biomassa de feijão preto com densidades de semeadura maiores.

A produção de sementes por planta foi maior no espaçamento de $51 \mathrm{~cm}$ (Tabela 3). É importante se ressaltar que, no caso da produção de sementes, esse resultado não representa uma maior produção de

Tabela 1 - Modelos matemáticos estimados para biomassa e conteúdo de macronutrientes na parte aérea, número de sementes e número e peso de nódulos de fixação biológica de nitrogênio em Lupinus albescens.

\begin{tabular}{llll}
\hline Variável dependente & \multicolumn{1}{c}{ Modelos matemáticos } & $\mathrm{R}^{2}$ & $\mathrm{CV} \%$ \\
\hline $\mathrm{MS}$ & $\mathrm{MS}=11-0,2805 \mathrm{EL}+0,002491 \mathrm{EL}^{2^{*}}$ & 0,97 & 29,58 \\
$\mathrm{~N}$ & $\mathrm{~N}=87,56-2,1491 \mathrm{EL}+0,0177 \mathrm{EL}^{2 *}$ & 0,98 & 41,00 \\
$\mathrm{P}$ & não houve ajuste significativo para os modelos testados & - & - \\
$\mathrm{K}$ & $\mathrm{K}=17,2485+0,5899 \mathrm{EL}+0,008015 \mathrm{EL}^{2 *}$ & 0,97 & 35,67 \\
Mg & $\mathrm{Mg}=22,12-0,5823 \mathrm{EL}+0,0052 \mathrm{EL}^{2 *}$ & 0,96 & 38,57 \\
$\mathrm{Ca}$ & $\mathrm{Ca}=79,08-2,3938 \mathrm{EL}+0,0242 \mathrm{EL}^{2^{*}}$ & 0,94 & 53,50 \\
NS & $\mathrm{NS}=41,11+0,0879 \mathrm{EL}+0,0105 \mathrm{EL}^{2 *}$ & 1,00 & 30,50 \\
ND & $\mathrm{ND}=0,9+0,0452 \mathrm{EL}-0,0003806 \mathrm{EL}^{2^{*}}$ & 0,97 & 55,00 \\
PN & $\mathrm{PN}=13,55-0,2961 \mathrm{EL}+0,003373 \mathrm{EL}^{2^{*}}$ & 0,74 & 67,00 \\
\hline
\end{tabular}

\footnotetext{
* Significativo em $5 \%$ de probabilidade. (EL = espaçamento entre linhas; $\mathrm{MS}=$ biomassa da parte aérea; $\mathrm{N}=$ nitrogênio; $\mathrm{P}=$ fósforo; $\mathrm{K}=$ potássio; $\mathrm{Mg}=$ magnésio; $\mathrm{Ca}=$ cálcio; $\mathrm{NS}=$ número de sementes; $\mathrm{ND}=$ número de nódulos e $\mathrm{PN}=$ peso de nódulos).
} 
Tabela 2 - Valores estimados de produção de biomassa da parte aérea, conteúdo de nitrogênio $(\mathrm{N})$, potássio (K), cálcio $(\mathrm{Ca})$ e magnésio $(\mathrm{Mg})$ na biomassa da parte aérea de Lupinus albescens, em espaçamentos de 17, 34 e $51 \mathrm{~cm}$ entre linhas de semeadura.

\begin{tabular}{|c|c|c|c|c|c|}
\hline \multirow{2}{*}{ Espaçamento entre linhas } & \multirow{2}{*}{$\begin{array}{l}\text { Biomassa } \\
\text { Mg ha }^{-1}\end{array}$} & $\mathrm{~N}$ & $\mathrm{~K}$ & $\mathrm{Ca}$ & \multirow[b]{2}{*}{-------------- } \\
\hline & & --------- & 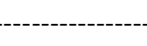 & $\mathrm{ha}^{-1}----------$ & \\
\hline 17 & 6,95 & 56,14 & 75,64 & 45,38 & 13,72 \\
\hline 34 & 4,34 & 34,95 & 47,65 & 25,67 & 8,33 \\
\hline 51 & 3,17 & 24,00 & 35,96 & 19,94 & 5,95 \\
\hline
\end{tabular}

Tabela 3 - Valores estimados para produção de sementes, número e peso de nódulos de fixação biológica de nitrogênio por planta de Lupinus albescens em espaçamentos de 17, 34 e $51 \mathrm{~cm}$ entre linhas de semeadura, a partir dos modelos gerados por análise de regressão.

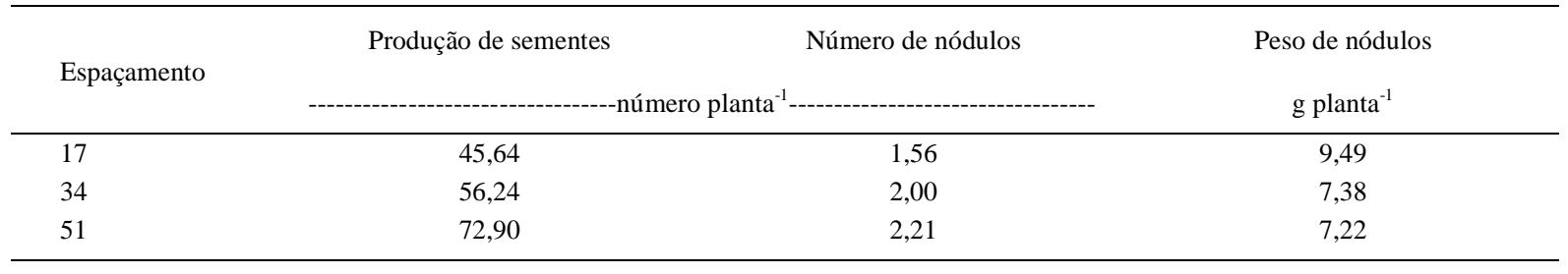

sementes por área, mas sim, por planta. Este pode ser um espaçamento entre linhas recomendável quando o plantio da espécie visa à produção de sementes.

\section{CONCLUSÃO}

O espaçamento entre linhas de $17 \mathrm{~cm}$ foi o mais eficiente para produção de biomassa e acúmulo de macronutrientes na biomassa da parte aérea, enquanto que o espaçamento de $51 \mathrm{~cm}$ apresentou melhor desempenho para a produção de sementes por planta. Conclui-se que é possível definir o espaçamento entre linhas de semeadura de acordo com o objetivo do plantio: de $17 \mathrm{~cm}$, para plantios de contenção da arenização, e de $51 \mathrm{~cm}$, para produção de sementes.

O número de plantas por metro linear não interferiu nas características analisadas, devendo ser então recomendado o menor número de sementes, tanto para a revegetação de áreas arenizadas, quanto em semeadura para produção de sementes.

\section{REFERÊNCIAS}

AZEVEDO, A.C.; KAMINSKI, J. Considerações sobre os solos dos campos de areia no Rio Grande do Sul. Ciência \& Ambiente, Santa Maria, v.11, p.71-80, 1995.

BOLDES, U. et al. Canopy flow and aspects of the response of plants protected by herbaceous shelterbelts and wood fences. Journal of Wind Engineering and Industrial Aerodynamics, Quebec, v.90, n.11, p.1253-1270, 2002. Disponível em: <http://www.sciencedirect.com/ science?_ob=ArticleURL\&_udi=B 6V3 M-46WW43 V$7 \&$ _user $=10 \&$ _coverDate $=11 \% 2 \mathrm{~F} 30 \% 2 \mathrm{~F} 2002 \&$ rdoc $=1 \&$
_fimt=high\&_orig=search\&_sort=d\&_docanchor=\&view=c\&_searchStrId $=1411973985 \&$ \&erunOrigin $=$ google $\&$ acct $=\mathrm{C} 0000502$ $21 \&$ _version $=1 \&$ _ur 1 Version $=0 \&$ _ userid $=10$

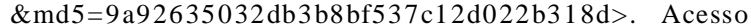
em: 8 dez. 2006. doi 10.1016/S0167-6105(02)00256-8.

CALEGARI, A. et al. Caracterização das principais espécies de adubo verde. In: CALEGARI, A. (Ed.). Adubação verde no sul do Brasil. 2.ed. Rio de Janeiro: AS-PTA, 1993. p.207324 .

COMISSÃO DE QUÍMICA E FERTILIDADE DO SOLO CQFS-RS/SC. Manual de adubação e calagem para os Estados do Rio Grande do Sul e de Santa Catarina. 10.ed. Porto Alegre: Sociedade Brasileira de Ciência do Solo - Núcleo Regional Sul/Universidade Federal do Rio Grande do Sul, 2004. $400 \mathrm{p}$.

COSGROVE, D. O mundo da natureza. In: BOYLE, C. (Ed.). Série história em revista. USA: Time-Life Books, 1991. $176 \mathrm{p}$.

D'ANTONIO, C.; MEYERSON, L.A. Exotic plant species as problems and solutions in ecological restoration: a synthesis. Restoration Ecology, Tucson, v.10, n.4, p.703-713, 2002. Disponível em: <http://www3.interscience.wiley.com/journal/ 118959562>. Acesso em: 15 abr. 2006. doi: 10.1046/j.1526100X.2002.01051.x.

EMPRESA BRASILEIRA DE PESQUISA AGROPECUÁRIA EMBRAPA. Centro Nacional de Pesquisas de Solos. Sistema brasileiro de classificação de solos. 2.ed. Rio de Janeiro: Embrapa Solos, Brasília, Sistema de Produção de Informação, 2006. 306p.

GISLER, S.D. Developing biogeographically based population introduction protocols for at-risk Willamette Valley plant species. Oregon, Salem: Native Plant Conservation Program, Oregon Department of Agriculture, 
2004. 179p. (Report to US Fish and Wildlife Service, Portland). Disponível em: <http://www.fws.gov/oregonfwo/species/Data/ B r a d s h a w s L o m a t i u m/ D o c u m e n t s / ODA2004ReportLomatiumBradshawii.pdf>. Acesso em: 7 jun. 2009.

KERSTIN, H.; LUNDMARK, J. Growth of nitrogen-fixing Alnus incana and Lupinus spp. for restoration of degenerated forest soil in northern Sweden. Studia Forestalia Suecica, Ostewala, n. 181, 1-20p. 1988. Disponível em: <http://wwwumea.slu.se/bibum/studia/index.cfm?volid=181>. Acesso em: 15 abr. 2009.

INSTITUTO BRASILEIRO DE GEOGRAFIA E ESTATÍSTICA - IBGE. Mapa de Biomas do Brasil, 2004. Acesso em: 15 jul. 2006. Online. Disponível em: 〈http://www.ibge.gov.br>.

KAGEYAMA, P.Y. et al. Implantação de matas ciliares: estratégias para auxiliar a sucessão secundária de Matas Ciliares. In: SIMPÓSIO SOBRE MATA CILIAR, 1989, Campinas, SP. Anais... Campinas: Fundação Cargill, 1989. p.130-143.

MOREnO, J.A. Clima do Rio Grande do Sul. Porto Alegre: Secretaria da Agricultura, Diretoria de Terras e Colonização, Secção de Geografia, 1961. 46p.

NAGANOWSKA, B. et al. Nuclear DNA content variation and species relationships in the Genus Lupinus (Fabaceae). Annals of Botany, Oxford, v.93, p.349-355, 2003. Disponível em: <http://aob.oxfordjournals.org/cgi/content/short/mcg145v1>. Acesso em: 11 fev. 2009. doi 10.1093/aob/mcg145.

PILLAR, V.P. et al. Estado atual e desafios para a conservação dos campos. In: WORKSHOP, 2006, Porto Alegre, RS. Anais... Porto Alegre: Instituto de Biociências, Universidade Federal do Rio Grande do Sul, 2006. 24p.
RESENDE, A.V.; KONDO, M.K. Leguminosas e recuperação de áreas degradadas. Informe Agropecuário, Belo Horizonte, v. 22 , n. 210 , p.46-56, 2001 .

ROVEDDER, A.P.M.; ELTZ, F.L.F. Revegetação com plantas de cobertura em solos arenizados sob erosão eólica no Rio Grande do Sul. Revista Brasileira de Ciência do Solo, Viçosa, v.32, n.1, p.315-321, 2008. Disponível em: <http:// www.scielo.br/scielo.php?script=sci_arttext\&pid=S0100$06832008000100029 \& \operatorname{lng}=\mathrm{pt}>$. Acesso em: 30 set. 2006. doi 10.1590/S0100-06832008000100029.

SANTOS, A.C. et al. Gramíneas e leguminosas na recuperação de áreas degradadas: efeito nas características químicas do solo. Revista Brasileira de Ciência do Solo, Viçosa, v.25, n.4 p.1063-1071, 2001. Disponível em: <http://www.sbcs.solos.ufv.br/solos/revistas/ v25n4a28.pdf>. Acesso em: 12 abr. 2006.

SUERTEGARAY, D.M. O Rio Grande do Sul descobre os seus desertos. Ciência \& Ambiente, Santa Maria, v.11, p.33-52, 1995.

SUERTEGARAY, D.M.A. Deserto grande do sul: controvérsia. 2.ed. Porto Alegre: UFRGS, 1998. 130p.

TEDESCO, M.J. et al. Análises de solo, plantas e outros materiais. 2.ed. Porto Alegre: UFRGS, 1995. 174p.

ZABOT, L. et al. Análise de crescimento da cultivar de feijão BR IPAGRO 44 Guapo Brilhante cultivada na safrinha em quatro densidades de semeadura em Santa Maria - RS. Revista de Ciências Agroveterinárias, Lages, v.3, n.1, p.105-115, 2004. Disponível em: <http://www.rca.cav.udesc.br/ rca_2004_2/zabot.pdf>. Acesso em: 21 out. 2006. 